\title{
Anthropometric indices independent of age for nutritional assessment in schoolchildren
}

\author{
D. SUBASH BABU ${ }^{1}$ AND C. S. CHUTTANI ${ }^{2}$
}

From the ${ }^{1}$ Health Department, Floriana, Malta, and the ${ }^{2}$ Department of Preventive and Social Medicine, University College of Medical Sciences, New Delhi

SUMMARY The merits of three indices based on weight $(\mathrm{W})$ and height $(\mathrm{H})$ were examined in the age group six to 15 years: $\mathrm{W} / \mathrm{H}, \mathrm{W} / \mathrm{H}^{2}, \mathrm{~W} / \mathrm{H}^{3}$. The analysis was based on a survey of 1673 schoolchildren of both sexes from a rural housing block in Delhi. It showed that the index W/ $\mathrm{H}^{2}$ was invariant with age in the range six to 15 years and that the other two indices were biased with respect to age. The index $\mathrm{W} / \mathrm{H}^{2}$ was found to be of value for the proper assessment of nutritional status in the schoolchildren of a developing country.

Anthropometric indices independent of age for the assessment of nutritional status are badly needed, especially in developing countries where the correct age of a child is difficult to elicit. A reliable, practicable, single index would be extremely useful in these countries. Weight and height are the commonly used measurements for assessing nutritional status. Some studies have been reported, in the literature on adults, of the suitability of the indices derived from weight $(\mathrm{W})$ and height $(\mathrm{H}): \mathrm{W} / \mathrm{H}, \mathrm{W} / \mathrm{H}^{2}, \mathrm{~W} / \mathrm{H}^{3}$. All these indices were found to be well correlated with relative adiposity (Billewicz et al., 1962), but only $\mathrm{W} / \mathrm{H}^{2}$ was found to be independent of height. In another study, it was confirmed that $\mathrm{W} / \mathrm{H}^{2}$ was highly correlated with weight, and it was independent of height in industrial workers in Birmingham (Khosla and Lowe, 1967). Also, in a study in India of preschool children, it was observed that the index $\mathrm{W} / \mathrm{H}^{2}$ was a suitable measure for nutritional assessment, and that it was independent of age, height and sex (Visweswara and Singh, 1970). However, similar attempts to evaluate the usefulness of this index in groups of school age seem to be lacking. In this paper an attempt is made to study the relative merits of the three indices in schoolchildren aged six to 15 years.

\section{Material and methods}

A general health survey was carried out among schoolchildren in the rural areas of one of the blocks in Delhi. All the children attending school in seven villages of the block were examined. Records were kept on a special pro forma, but only those children without clinical evidence of disease $(82.3 \%)$ were considered.
A total of 1673 children aged six to 15 years were included in the study, of whom $54 \%$ were boys. Height was recorded in $\mathrm{cm}$ without shoes, and weight in $\mathrm{kg}$ with light clothing, using standard equipment which was tested for accuracy from time to time.

\section{Results}

Table 1 gives the basic results for mean height and mean weight, with standard deviations for both boys and girls at each year of age from six to 15 years. Table 2 shows the means and standard deviations of the bulk index $\frac{\text { weight }}{\text { height }} \times(100)$. Fig. 1 shows a comparison of trends in mean height and weight with age in children of both sexes. Figs. 2 and 3 compare the trends of the indices $\mathrm{W} / \mathrm{H}, \mathrm{W} / \mathrm{H}^{2}, \mathrm{~W} / \mathrm{H}^{3}$, relative to the values of the corresponding indices at the age of six years considered as $100 \%$.

\section{Discussion}

Boys are taller than girls at each age but the difference in height tends to diverge with age (Fig. 1). At each age, the boys are heavier than the girls, and the difference in weight, like that in height, also increases with age. The mean height of boys in this study was greater by about $1-2 \mathrm{~cm}$ in every age group compared with the findings of the Indian Cotuncil of Medical Research (ICMR) on rural standards (ICMR, 1972). For girls up to the age of eight years, mean height showed a trend similar to that for boys, but after the age of eight years, mean height was 1-2 $\mathrm{cm}$ less compared with the ICMR standards. Although they were taller at every age, the boys in this study weighed less after the age of 11 , and the 
Table 1 Mean height and weight of schoolchildren by age and sex

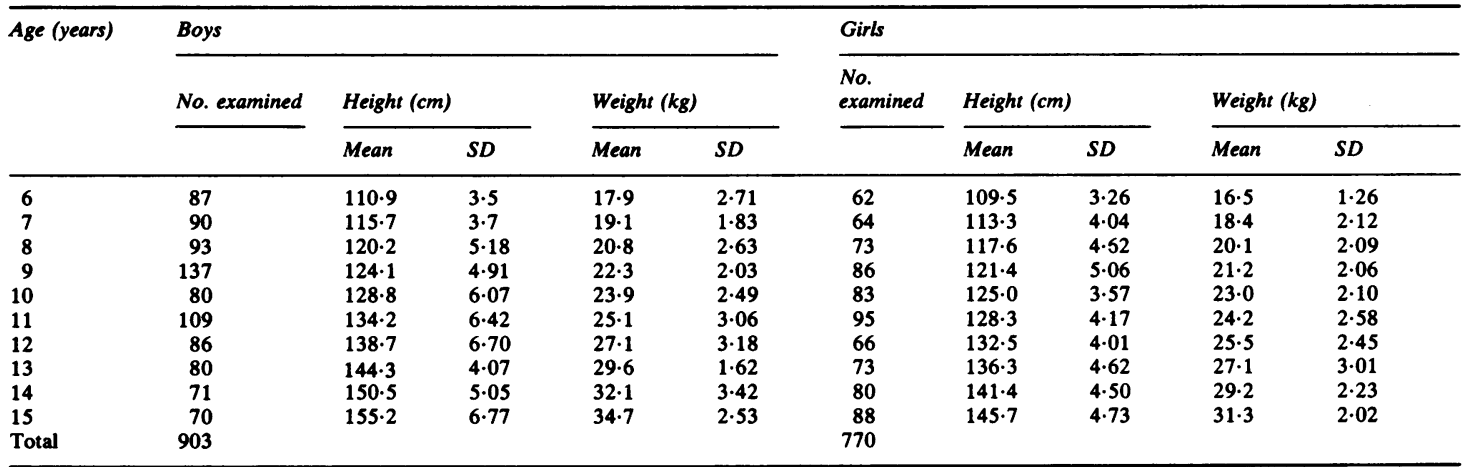

Table 2 Means and standard deviations of bulk index $\frac{\text { weight }}{\text { height }} 2 \times(100)$

\begin{tabular}{|c|c|c|c|c|}
\hline \multirow[t]{3}{*}{ Age (years) } & \multicolumn{4}{|c|}{ Bulk index } \\
\hline & \multicolumn{2}{|l|}{ Boys } & \multicolumn{2}{|l|}{ Girls } \\
\hline & Mean & $S D$ & Mean & $S D$ \\
\hline 6 & 0.1448 & 0.0116 & 0.1401 & 0.0114 \\
\hline 7 & 0.1431 & 0.0120 & 0.1414 & 0.0109 \\
\hline 8 & $0 \cdot 1452$ & 0.0127 & 0.1419 & 0.0138 \\
\hline 9 & $0 \cdot 1443$ & 0.0141 & 0.1414 & 0.0116 \\
\hline 10 & $0 \cdot 1447$ & 0.0114 & 0.1409 & 0.0108 \\
\hline 11 & 0.1444 & 0.0129 & 0.1405 & 0.0113 \\
\hline 12 & $0 \cdot 1450$ & 0.0141 & 0.1398 & 0.0132 \\
\hline 13 & $0 \cdot 1446$ & 0.0131 & 0.1396 & 0.0165 \\
\hline 14 & 0.1454 & 0.0112 & 0.1413 & 0.0151 \\
\hline 15 & $0 \cdot 1456$ & 0.0116 & 0.1426 & 0.0146 \\
\hline
\end{tabular}

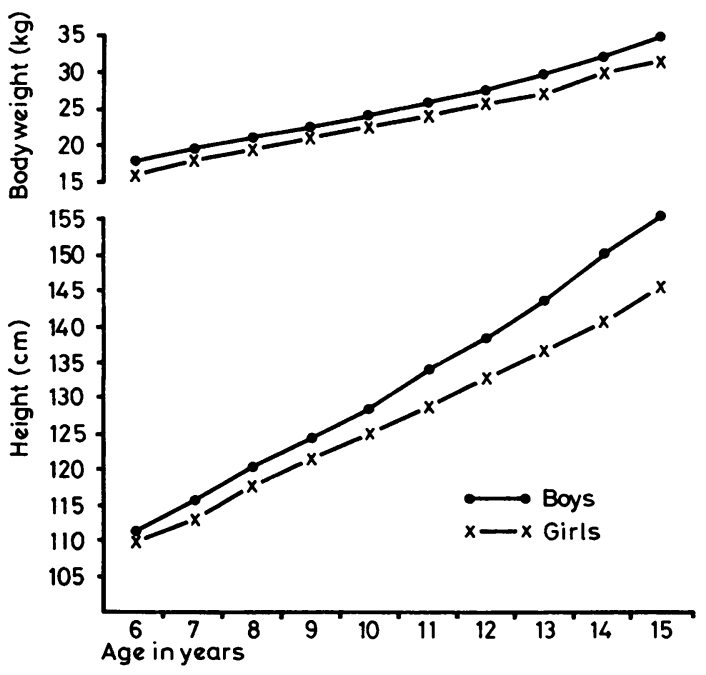

Fig. 1 Trends in mean height and weight with age (6-15 years). girls weighed less at every age, by comparison with the ICMR standards. These variations might be due to the fact that these standards were calculated in 1970 or thereabouts, on the basis of the total rural population of India. In our study, carried out in 1977, rural schoolchildren in Delhi only were considered. More research is needed to explore the reasons for these differences in weight. The finding that the children from Delhi rural areas are lighter, height for height, than the ICMR standards is a matter for concern, because, on average, the people of the rural areas around Delhi would be expected to be far better off economically than those in most of the other rural areas in India.

Figs. 2 and 3 show that the index $\mathrm{W} / \mathrm{H}$ increases with age and the index $\mathrm{W} / \mathrm{H}^{3}$ decreases with age in both boys and girls. Both these indices are seriously biased with respect to age. But the index $\mathrm{W} / \mathrm{H}^{2}$ is invariant with age in the range six to 15 years for both boys and girls. The use of the index $\mathrm{W} / \mathrm{H}$ or $\mathrm{W} / \mathrm{H}^{3}$ can produce misleading conclusions.

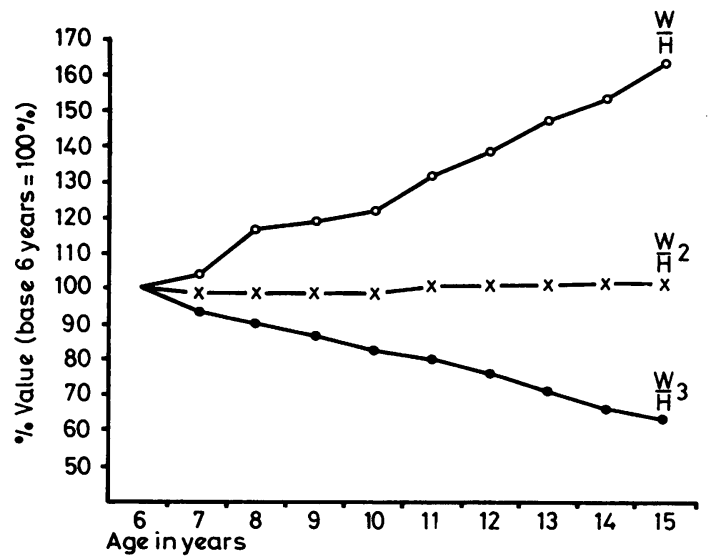

Fig. 2 Trends of indices with age (boys). 


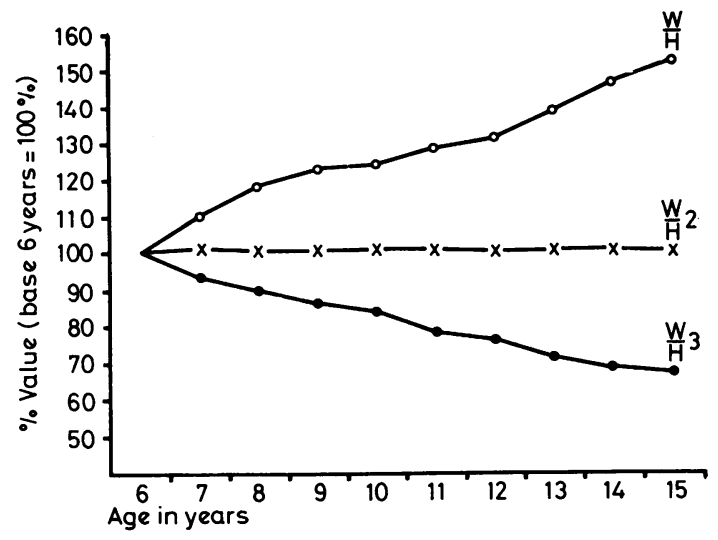

Fig. 3 Trends of indices with age (girls).

When examining the indices in this study, it can be inferred that the index $\mathrm{W} / \mathrm{H}^{2}$ is independent of age in the range six to 15 years. This age-independent index has practical value in developing countries like India-especially in rural areas- where the exact age of children may be difficult to ascertain when studying nutritional status. The index $\mathrm{W} / \mathrm{H}^{2}$ is found to be invariant with height in the adult age range. It appears that the index is suitable for all ages in both sexes including children of preschool age in India.

We thank Dr. T. Khosla for helpful comments.

Reprints from Dr. D. Subash Babu, consultant in public health, Health Office, 6, Harper Lane, Floriana, Malta.

\section{References}

Billewicz, W. Z., Kemsley, W. F. F., and Thomson, A. M. (1962). Indices of adiposity. British Journal of Preventive and Social Medicine, 16, 183.

Indian Council of Medical Research. (1972). Technical Report Series No. 18. ICMR: Delhi.

Khosla, T., and Lowe, C. R. (1967). Indices of obesity derived from body weight and height. British Journal of Preventive and Social Medicine, 21, 122.

Visweswara, Rao, K., and Darshan Singh (1970). An evaluation of the relationship between nutritional status and anthropometric measurement. American Journal of Clinical Nutrition, 23, 83. 